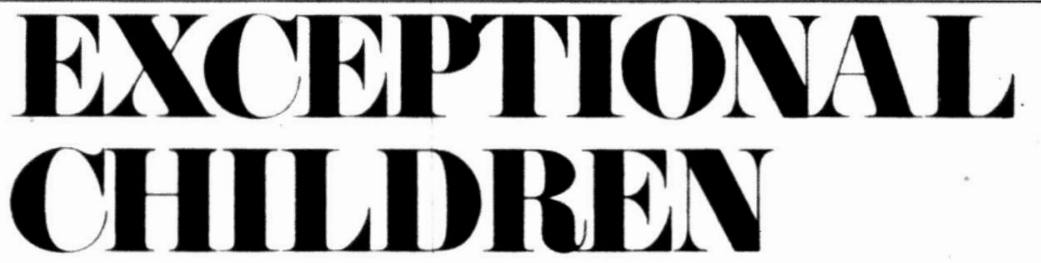

\title{
DEVELOPING PROGRAMS FOR SEVERELY HANDICAPPED STUDENTS: TEACHER TRAINING AND CLASSROOM INSTRUCTION
}

\section{Lou Brown and Robert York ${ }^{1}$}

\section{PROGRAMMING FOR THE SEVERELY HANDICAPPED}

This paper is intended to relate to some of the problems confronting those persons who are attempting, through the preparation of personnel, to generate quality services for severely handicapped students. In the recent past there have been several events of vital importance to the nature of services available to severely handicapped students. These events may be referred to as judicial-legislative actions. For a more historical and technical treatment of these judicial-legislative actions, the reader is referred to Gilhool (1973), Lippman and Goldberg (1973), and Schwartz (1973). Our admittedly unsophisticated interpretation of these events goes something like this. Children need to be included in, not excluded from, public school programs because they are "too something or other." That is, too custodial, too retarded, too disturbed, too autistic, too nonambulatory, too sick, etc. The parents and friends of severely handicapped children realized this, obtained counsel, and asked a group of judges for reasons why some children could go to school and other children could not. The judges found the reasons offered by others inadequate (e.g., no money, no room, no teachers, can't benefit) and ruled that all children should have equal access to public services. That is, if one child is entitled to a free public education, then all children are entitled to such a service.

Once one group of judges decided that all children had a right to the same public services, it became apparent that other judges in similar cases would probably reach the same conclusion. Thus, many state legislatures, involved in or anticipating similar litigation, enacted laws providing for free public education for all children within their borders (e.g., Washington, Wisconsin, and Michigan). Our purpose here is not to delineate the important and at times devastating implications of such comprehensive legislative and judicial actions. Rather we are assuming that in the very near future all children in the nation, regardless of level of functioning, will have access to a free public education. Thus, in our judgment, the issue now becomes how can we provide the best possible developmental services to the lowest functioning children in our society.

1. Lou Brown is Associate Professor and Robert York is Research Assistant, Department of Studies in Behavioral Disabilities, University of Wisconsin, Madison.

- Love Publishing Company, 1974 
Obviously, if a large number of severely handicapped children will be provided for in public school settings, a large number of special educators will be needed to develop and implement instructional programs for these newly acknowledged students. For the past several years, the writers and their colleagues have been attempting to prepare teachers who have the technological repertoires necessary to provide reasonable instructional services to these students both in public school and in residential settings. In the sections that follow we will attempt to delineate several of the basic components of an evolving teacher training model that we have found useful.

\section{WHO ARE SEVERELY HANDICAPPED STUDENTS?}

The generic term "severely handicapped" as it is used here refers to children who have been given such labels as "low functioning," "trainable retarded," "severely emotionally disturbed," "severely retarded," "psychotic," "autistic," "custodial," "developmentally young," "schizophrenic," "subtrainable," "dependent," "multiply handicapped," "vegetables," and the like. Many of these children, until recently, have been excluded from public school programs because of various social, sensory-motor, behavioral, and intellectual deficits. Perhaps, more specifically, "severely handicapped"

...includes students who are not toilet trained; aggress toward others; do not attend to even the most pronounced social stimuli; self-mutilate; ruminate; self-stimulate; do not walk, speak, hear, or see; manifest durable and intense temper tantrums; are not under even the most rudimentary forms of verbal control; do not imitate; manifest minimally controlled

FOCUS ON EXCEPTIONAL CHILDREN is published monthly except June, July, and August as a service to those concerned with mentally retarded and emotionally disturbed children. This journal is abstracted and indexed in Exceptional Child Education Abstracts. Subscription rates, $\$ 9.50$ per year. Copyright 1974, Love Publishing Company. All rights reserved. Reproduction in whole or part without written permission is prohibited. Printed in the United States of America. Second class postage is paid at Denver, Colorado.

$$
\begin{gathered}
\text { Executive and Editorial Offices } \\
6635 \text { East Villanova Place } \\
\text { Denver, Colorado } 80222 \\
\text { Telephone (303) } 757-2579
\end{gathered}
$$

\section{EDITORIAL BOARD}

Edward L. Meyen

University of Kansas

Richard J. Whelan

University of Kansas Medical Center
Sallie Carmachel Keeney

Managing Editor
Glenn A. Vergason Georgia State University

Stanley F. Love Publisher seizures; and/or have extremely brittle medical existences. [Sontag, Burke, and York, 1973]

It should be noted that the term severely handicapped, as it is used here, did not emanate from a scholarly treatment of complex and dynamic categorical parameters germane to the categorization of children, but as a result of other more banal experiences. Namely, if students do not speak, follow directions, imitate, play with peers, control their own behavior, etc., they are severely handicapped in their ability to function in society and need to be taught such skills to do so. Given the developmental level of current assessment instruments and inferential measurement, we find little instructional validity in such terms as autistic, severely retarded, or low functioning. Therefore, we have chosen to refer to such individuals as "severely handicapped." It should be realized that the term is for the most part irrelevant to instructional programming and simply provides a generic name for the population of individuals discussed here. In the public school classrooms in which we are involved, almost every diagnostic label imaginable can be found by searching students' cumulative records. In addition, these individuals have spent time in nearly every type of service delivery system available (e.g., institutions for the mentally retarded, mentally ill, and emotionally disturbed; local ARC programs; private schools for exceptional children).

Thus, we have found it expedient to classify students into two social and academic functioning levels: mild and severe. The discrimination problems attendant to delineating the presumed differences between "emotionally disturbed," "mentally retarded," or "learning disabled" students can now be focused upon the differences between "mild" and "severe." However, such problems are in the hands of school psychologists, social workers, and administrators-with teacher attention being focused upon grouping and instructing children along relevant educational dimensions.

\section{THE PROBLEM OF SELECTION AND RECRUITMENT}

When attempting to develop a college or university based training program for teachers of severely handicapped students, there are several inherent impediments that must be confronted.

First, extremely few college students have had exposure to severely handicapped children prior to entering college. Unfortunately, this lack of exposure in many cases results in people not even knowing that such children exist. Second, there are very few college students who start their careers with a strong inclination toward becoming teachers of severely handicapped students. Third, there seems to be 
a pecking order within special education. That is, it is apparently more glamorous for college students to manifest interest in becoming teachers of emotionally disturbed students or children with special learning disabilities than it is for them to declare interest in becoming teachers of severely handicapped students. Fourth, even though a person does manifest an interest in working with severely handicapped students, it does not necessarily mean that he or she will be an effective tefacher. That is, there are people who have a mongoloid uncle or who have heard that there are going to be jobs open in the future for teachers of severely handicapped children and base their career decisions accordingly. We have found very little predictive validity in such factors.

Obviously, we have encountered such barriers and over a period of years have evolved compensatory actions that might be of interest to others. First, we offer a relatively large lecture course entitled "Introduction to Mental Retardation." Usually about 75-100 students enroll in this course each semester. The course is structured in such a way that students have an option of working with severely handicapped persons or taking standard university type tests. Over the past 8 semesters, 99.9 percent of the students who have taken the course have chosen to work with severely handicapped persons. Some of the settings in which these students work are in schools operated by the Madison Area Association for Retarded Citizens (programs for preschool and post school age persons), Central Wisconsin Colony (a residential facility for severely and profoundly retarded persons ranging in age from birth to ages 50-60), the Madison Public Schools, and a local nursing home for retarded adults.

Two of the few criteria of these practicum placements are (1) that the students work with professionals at the various facilities, and (2) that they make at least 2 trips per week for at least $1 / 2$ hours per trip. After these practicum placements are arranged, those responsible for teaching the course visit the various facilities and talk to the professionals about the performance and capabilities of the university students under their supervision. The basic question asked of the professionals in the various facilities is "Who do you have that in your judgment will be a good teacher of severely handicapped students?" Responses to such a question usually result in a list of about $40-45$ students. The professor in charge of the course then invites those delineated individually or in small groups to his office for coffee, etc., to discuss the possibilities of pursuing a career as a teacher of severely handicapped students. Usually, about 15 students per semester come to realize that what they have always wanted was a career teaching severely handicapped students. Obviously, the interaction between the recruiting professor and the student is crucial. However, the exact content of the conversations is perhaps inappropriate for presentation here. The point is that this is one vehicle that might be used to select and recruit potential teachers. Certainly there are other approaches, and we are sure that as preparation programs designed to train teachers of severely handicapped students develop over the country other vehicles will evolve.

\section{THE NEED FOR PRE-LICENSE PRACTICUM INVOLVEMENT}

Most children, even mildly handicapped children (i.e., children with learning disabilities, educably mentally retarded, and mildly emotionally disturbed children), come to school with reasonably well developed behavioral repertoires. That is, most students come to school toilet trained, with the ability to speak in varying degrees of fluency, with the ability to follow complex verbal directions, with the ability to play with peers with minimal supervision, with relatively complex receptive language skills, and with some ability to work alone in a constructive manner. Thus, teachers of normal and mildly handicapped children have many valuable social and emotional foundations upon which they can base their instructional systems. In addition, as teachers have usually been playing with and otherwise relating to children throughout their lives, there are many skills that teachers have acquired that are directly relevant to the job requirements needed for teaching mildly handicapped or normal children.

Obviously, all children are alike in some ways and, obviously, all children are uniquely individual in some ways. Unfortunately, severely handicapped children in many ways are dramatically different from their age peers. Thus, teachers of severely handicapped children require different teacher-child interaction skills. For example, such general approaches like "He'll grow out of it." "She'll learn to do it another way." "Just leave him alone." "You have to give her time." etc., are simply not applicable. Severely handicapped children may never "grow out of it," and they may never "try another way." Thus, we have found it necessary to provide teachers in training with intense and durable experiences with severely handicapped children. Several of the specifics related to these experiences are presented in another section of this paper. Perhaps it is appropriate here to present in outline form the structure of a typical pre-license practicum sequence.

First, a student will spend at least 3 hours per week working under professional supervision, usually in a nonpublic school setting, for 16 weeks or a total of 48 contact hours. Subsequently, students will spend 4 hours per day, 
5 days per week for 16 weeks or a total of 320 contact hours in a public school classroom for severely handicapped students as part of a pre-practice teaching "methods course." Finally, students will spend 4 hours per day, 5 days per week for 16 weeks as a "practice teacher" in a public school classroom for severely handicapped students. Thus, across 3 semesters a student will spend approximately 680 contact hours with severely handicapped students under the supervision of various professionals.

Such a durable and intense practicum sequence is certainly not unique to special education nor is it a guarantee that a student will acquire the skills necessary to perform well as a teacher. However, in our judgment this kind of sequence and involvement is at least necessary, however insufficient.

\section{A WORKING DEFINITION OF TEACHING}

In an attempt to deemphasize the tendency to focus on aspects of severely handicapped students that classroom instructional personnel can do little if anything about (e.g., genes, brains, prenatal experiences, poor protoplasm), we have evolved a tentative definition of teaching.

Severely handicapped children are considered severely handicapped because they cannot perform skills that other children can perform. The dependent variables in an instructional setting are changes in the behavioral repertoires of the students. Thus, teaching refers to or may be defined as the creation or arrangement of an environment that produces specified changes in the behavioral repertoires of the students. This definition, of course, is an extreme oversimplification of a complex and dynamic construct and may have little if any utility for someone teaching poetry to gifted adolescents. Nevertheless, we have found substantial practical value in such a definition for at least the following reasons:

1. This definition requires that a delineate or specify precisely the response the students will perform that they are not nov performing in the presence of the teacher. In iffect, the teacher becomes an instructional determinist.

2. This definition requires that a teacher delineate or specify precisely the activities or behaviors in which he or she will engage that are expected to enhance the behavioral repertoires of the students. In effect, the teacher becomes an instructional environmentalist in that attention is focused almost exclusively on factors in the instructional environment (outside the body of the student) that the teacher can in some degree manipulate.

3. This definition requires that a teacher verify the existence of changes in the behavioral repertoires of the students. In effect, the teacher becomes an instructional empiricist in that changes in the students must be operationally defined and sensed. ${ }^{2}$

Thus, in our view, it seems reasonable to require a teacher of severely handicapped students (1) to specify what responses, skills, concepts, etc., he or she intends for the student to acquire, (2) to specify how he or she intends to impart such responses, skills, concepts, etc., and (3) to measure whether or not the students have the responses, skills, concepts, etc., in their behavioral repertoires.

On the other hand, the reader should be forewarned that when teachers of severely handicapped students attempt to adhere to the criteria of this particular definition of teaching they are assuming an unusual instructional responsibility. That is, they cannot claim or continue to claim the title of teacher until they have demonstrated that they have induced students to acquire skills or continue to induce students to acquire skills that they have not manifested previously. In other words "if I cannot engage in activities that result in changes in the repertoires of my students, I cannot claim to be a teacher."

\section{INSTRUCTIONAL COMPETENCIES}

If a teacher adheres to the criteria of the definition of teaching presented above (i.e., teaching is changing students in demonstrable ways), then an instructional repertoire of behavioral competencies becomes crucial. Potential teachers can accrue grade point averages of 4.0 , they can talk in university seminars for hours about changing society, changing schools, relating to children, grasping the fundamentally transcendental nature of emotive childteacher interactions, etc., but they cannot claim to be teachers until they have changed students in demonstrable ways.

While the quest for competency based models of instruction has been present in education for centuries, several factors have contributed to unusual recent concern. First, there is less of a shortage of licensed teachers now than ever before. Thus, many persons are less concerned

2. For a further discussion of instructional determinism, environmentalism, and empiricism, the reader is referred to Brown, 1973. 
with quantity and filling orders. Second, recent conceptual and empirical developments in the business community and in certain Federal government programs (e.g., the space program) related to systems analysis approaches to problem solving have permeated the thinking of many school administrators in the form of "management by objective contracts" (Vergason, 1973). This management by objectives approach is now becoming discernable in relation to the performance of teachers in classrooms. Third, the general mood of the country in the 1970s both politically and economically has shifted to the right of the general mood of the 1960 s. This mood swing has brought to the fore ideas that many educators find disconcerting to say the least. Such concepts as cost-effectiveness, accountability, behavioral objectives, and long range manpower needs have put new pressures upon school administrators, treachers, and teacher training institutions. Competency based teacher training models are but one of the manifestations of these new pressures.

One view of an instructional competency is as follows: an instructional competency is a set of behaviors a teacher engages in that result in empirically verifiable changes in the behavioral repertoires of the students in his or her charge. For example, assume that a teacher determines that a student should demonstrate the skill of correctly adding any 2 numerals that total 10 or less (predictable change). The teacher then must arrange an instructional environment (engage in behaviors) that results in the student's performing such skills. If the student does not perform the skills, then it must be assumed that the teacher does not have the competencies necessary to teach them. Stated another way, "the person cannot claim to have taught because it has not been demonstrated that anything was changed."

If this view of instructional competencies is imposed upon teacher training institutions, several interesting phenomena might occur. It is the rare teacher training institution indeed that claims to produce incompetent teachers. If the training institution claims to produce competent teachers, then it is responsible for empirically verifying the specific competencies a particular teacher has acquired. If training institutions opt for competencies as they have been described here, then most paper-pencil tests of competencies are irrelevant. Thus, potential teachers must be able to demonstrate that they can change public school students in prescribed ways before they receive a license to teach. Just as parents have the right to expect that physicians have demonstrated skills necessary to cure certain ailments before the physician is exposed to their children, parents have the right to expect that teachers have demonstrated skills necessary to teach before the teacher is exposed to their children.
The position proposed here is that severely handicapped students are often dramatically different, if only in degree, from mildly handicapped students and thus need teachers with different competencies. For example, most severely handicapped students manifest severe speech and language deficits, severe behavioral management problems, severe imitation deficits, severe academic skill acquisition deficits. Thus, a competency based training model must require that potential teachers have demonstrated that they have taught severely handicapped students to speak, to communicate, to imitate, to perform basic academic skills, to behave appropriately, etc., prior to obtaining a teaching license.

Perhaps a quote from Sontag, Burke, and York (1973) is appropriate here:

In our view, there is a direct relationship between the level of the students' disability and the competencies of the teachers, i.e., the more pronounced the level of disability, the more specific and precise are the competencies required of the teachers. Most nonhandicapped and mildly handicapped students acquire information and skills from many diverse and nebulous sources: parents, teachers, siblings, peers, TV, toys, etc. These children can develop in spite of a poor teacher or an unconcerned parent. However, severely handicapped students have not been able to acquire the general basic skills and information in any way, from anyone, or anything. Therefore, unless drastic environmental manipulations are engineered, severely handicapped students will not be able to acquire the needed general basic skills and information. Procedures that are typically used by parents, TV producers, siblings, and most classroom teachers to impart skills and information to nonhandicapped and mildly handicapped students are of little utility with severely handicapped students.

The issue then becomes "What competencies are needed by the teachers of severely handicapped students?" In our view, the teachers' competencies are directly related to the instructional problems and acquisition deficits presented by the students. Thus, if the students are not toilet trained, but are physically capable of becoming so, the teacher must have within her instructional repertoire an applicable technology which will result in such students becoming toilet trained. If students are nonimitative, nonverbal, and/or do not attend or respond to social stimuli, then the teacher must be able to teach the students to speak, imitate, and/or to relate to social stimuli.

Concomitantly, the teachers must be able to do away with self-mutilating behavior, stereotypies, temper tantrums, and various escape and avoidance behaviors. In addition, the teachers must be able to teach the students to play with and acquire information from materials, self-feed, self-dress, ambulate, write, read, compute, etc. Finally, it is the teacher who will be the major source of practical information for the parents of the students in her charge. Thus, the teacher must be able to function as an effective parent-trainer.

At this point in time, it is a rare teacher who has been able to acquire all the skills needed to teach severely handicapped students merely from the experiences obtained in his or her college level special education training program. Assuming that the previous statement is accurate, then it seems logical that there are very few teachers in the field who have the competencies to teach severely handicapped students and that 
there are very few, if any, teacher training programs producing teachers with these needed competencies. Thus, most of the new classes arranged for these students will be staffed by untrained teachers.

During the past five years, the writers and their colleagues have at various times drafted lists of behavioral competencies without which a teacher of severely handicapped students presumably could not succeed. A detailed presentation of these lists is obviously inappropriate for inclusion here. However, it might be fruitful to delineate several of the categories that were articulated:

1. Techniques of managing severe behavior problems

2. Procedures for the development of teacher made instructional materials

3. The engineering of physical properties of classrooms

4. Basic principles of acquisition and performance

5. Basic principles and techniques of instructional measurement

6. Basic principles of imitation training, generalization, discrimination, and maintenance

7. Basic principles of task analysis

8. Development and implementation of instructional programs

9. Procedures used to develop curriculum sequences

It should be noted and emphasized that this is only a partial list of categories and that within each category substantial listings of behavioral competencies are mandatory. Thus, it was our objective to produce teachers with demonstrated behavioral competencies in each of the categories listed above. In all honesty we have found this task to be impossible. That is, we have been incompetent teacher trainers in that we have not demonstrated that our students could perform all the required competencies necessary for the provision of qualit instructional services to severely handicapped children. $\mathrm{C}$ hfortunately, we have had to resort to paper-pencil and ver oal ("Tell us what you would do if...") indications of potes tial classroom instructional performance (i.e., inferential measurement).

\section{COMPONENTS OF AN INSTRUCTIONAL PROGRAM}

We realize that in presenting this model of teaching severely handicapped students we are oversimplifying complex multi-person interactions. Nevertheless, we have found it advantageous to attempt to conceptualize many classroom activities into what may be referred to as instructional programs. An. instructional program in our view may be conceptualized as consisting of at least 4 not necessarily mutually exclusive components: content, method, materials, and measurement.

\section{Content}

Content refers to the what of instruction. That is, if the teacher asks the question "What do I want a student to be able to do that he could not do in the past?" he or she is asking a content question. Content refers to specific responses students might make when presented with specified stimuli. Most available "curriculum guides" are composed primarily of instructional content or information related to what a teacher might decide to attempt to teach. However, rarely do curriculum guides contain the precision in content delineation mandatory for instructing severely handicapped students. That is, such guides rarely specify the specific responses to specific stimuli that a student is supposed to emit and what criteria or acceptable level of performance the child must achieve to be considered to have learned a task, Such precision in curriculum delineation is not new to education (Mager, 1962 , p. 12), it simply has not been utilized in the vast majority of curriculum guides.

In an attempt to realize precision in content delineation, we have found a task analysis approach quite useful. By a task analysis approach we mean that at some point in time a teacher takes the responsibility of determining what responses the students should make. This determination may be labeled the terminal objective. Once a teacher has specified a terminal objective, it is necessary that he or she divide the objective into steps or components that lead from responses in the student's present behavioral repertoire to the terminal objective. The teacher then arranges these steps in a series so that the student's progress through the series culminates in the performance of the terminal objective. These components may be extremely small bits of behavior taught separately and then chained together into the terminal objective, or they may become part of a more complex response as soon as they are acquired. If, for example, a child cannot move easily from step 5 to step 6 , then step 6 may be too demanding and parhaps there should be a step 51/2. Increasingly finer breakdowns (slicing) of the curriculum or the elimination of unnecessary steps are constant aspects of the task analysis process as one goes from the teacher constructed task analysis to the task analysis required by the student to achieve the terminal objective. Bateman (1971) describes this process 
as a progression from a logical task analysis (that constructed initially by the teacher) to an empirical task analysis (that actually necessary for the student to perform the terminal objective). Thus, a task analysis approach is always a dynamic process in which it is most likely that any given task analysis will be modified for individual students.

The following is an ex.ymple of a task analysis currently being developed for use in a public school classroom for young severely handicapped students (Swetlik, 1974). This task analysis emanated from two teacher observations. First, it was observed that in many situations requiring expressive or receptive verbal language the students were not using or comprehending personal pronouns appropriately. Second, the students did not appear to comprehend personal pronouns when they were included in reading material. Thus, the appropriate use and comprehension of personal pronouns were judged crucial longitudinal language and reading skills. The teacher then attempted to develop an instructional program that would result in the development of selected uses of personal pronouns. What follows is the task analysis component of that program.

\section{TEACHING LOW FUNCTIONING STUDENTS $(S \mathrm{~s})$ SELECTED FIRST, SECOND, AND THIRD PERSON SINGULAR PRONOUN EXPRESSIVE LANGUAGE RESPONSES TO “WHO-DOING” QUESTIONS}

\section{Task Analysis II}

Phase I: Verifying that $S$ s could imitate selected 1,2, and 3 word verbal responses.

Part 1 - Verifying that $S$ s could imitate one word verbal responses (e.g., I).

Part 2 - Verifying that $S$ s could imitate 2 word verbal responses (e.g., I am.).

Part 3 - Verifying that $S$ s could imitate 3 word verbal responses (e.g., I am sitting.).

Phase II: Teaching $S$ s to perform actions in response to verbal cues, to visually discriminate actions, and to label actions.

Part 1 - Teaching $S$ s to perform actions in response to verbal cues (e.g., Show me standing.).

Part 2 - Teaching $S$ s to visually discriminate actions (e.g., Touch someone standing.).

Part 3 - Teaching $S$ s to label actions (e.g., What is Joe doing?).
Phase III: Teaching $S$ s to visually discriminate (touch) self, teacher $(T)$, and peers in response to name cues.

Part 1 - Teaching $S$ s to visually discriminate (touch) self in response to a name cue.

Part 2 - Teaching $S$ s to visually discriminate (touch) $T$ in response to a name cue.

Part 3 - Teaching $S$ s to visually discriminate (touch) peers in response to name cues.

Part 4 - Teaching $S$ s to visually discriminate (touch) self, $T$, and peers in response to name cues.

Phase IV: Teaching $S$ s to visually discriminate males and females using 3 rd person singular subject pronoun cues (e.g., Touch a he. Touch a she.).

Part 1-Teaching $S$ s to visually discriminate males using the 3rd person singular subject pronoun cue he (e.g., Touch a he.).

Part 2 - Teaching $S$ s to visually discriminate females using the 3 rd person singular subject pronoun cue she (e.g., Touch a she.).

Part 3 - Teaching $S$ s to visually discriminate males and females using the 3 rd person singular subject pronoun cues he and she (e.g., Touch a he. Touch a she.).

Phase $V$ : Teaching $S$ s to make identity responses (proper name responses) to "who" questions containing 1st, 2nd, and 3 rd person singular subject pronouns.

Part 1- Teaching $S$ s to label $T$ in response to "who" questions containing the 1 st person singular subject pronoun $I$ (e.g., Who am I?).

Part 2 - Teaching Ss to label self in response to "who" questions containing the 2 nd person singular pronoun you (e.g., Who are you?).

Part 3 - Teaching $S$ s to label $T$ and self in response to "who" questions containing the 1st and 2nd person singular subject pronouns $I$ and you (e.g., Who am I? Who are you?).

Part 4 - Teaching $S$ to label male peers in response to "who" questions containing the 3rd person singular subject pronoun he (e.g., Who is he?).

Part 5 - Teaching $S$ s to label female peers in response to "who" questions containing the 3 rd person 
singular subject pronoun she (e.g., Who is she?).

Part 6 - Teaching $S$ s to label male and female peers in response to "who" questions containing the 3rd person singular subject pronouns he and she (e.g., Who is he? Who is she?).

Part 7 - Teaching $S$ s to label themselves, $T$, and male and female peers in response to "who" questions containing the $1 \mathrm{st}$, 2nd, and $3 \mathrm{rd}$ person singular subject pronouns (e.g., Who am I? Who are you? Who is she/he?).

Phase VI: Teaching Ss to respond to "Who-doing?" questions with the 1st person singular subject pronoun and present progressive verbs (e.g., Q: Who is standing? A: I am standing.).

Phase VII: Teaching Ss to respond to "Who-doing?" questions with the 2nd person singular pronoun and present progressive verbs (e.g., Q: Who is standing? A: You are standing.)

Phase VIII: Teaching $S$ s to respond to "Who-doing?" questions with 3 rd person singular subject pronouns and present progressive verbs (e.g., Q: Who is standing? A: $\mathrm{He} /$ She is standing.).

Part 1- Teaching Ss to respond to "Who-doing?" questions with the 3 rd person singular pronoun he (e.g., He is standing.).

Part 2 - Teaching Ss to respond to "Who-doing?" questions with the 3 rd person singular pronoun she (e.g., She is standing.).

Part 3 - Teaching $S$ s to respond to "Who-doing?" questions with the 3 rd person singular pronouns he or she.

Phase IX: Teaching $S$ s to respond to "Who-doing" questions with singular subject pronouns (1st, 2nd, and 3rd person) and present progressive verbs (e.g., Q: Who is standing? A: I am standing. Q: Who is standing? A: You are standing. Q: Who is standing? $\mathbf{A}$ : He is standing. Q: Who is standing? A: She is standing.).

Another aspect of task analysis crucial to the teacher of severely handicapped students that should be made salient is its relationship to assessment. A teacher confronting a severely handicapped student for the first time can learn little about the new student from the information obtained from traditional asssessment instruments (IQ tests, achievement tests, etc.). A technique of much greater instructional relevance is that of individual assessment on components of specific task analyses. This approach requires that the teacher proceed through each of the steps of the analysis he or she has developed for each of the tasks being taught in the classroom. Instruction would then begin on those steps performed incorrectly by the student and proceed sequentially through more difficult steps. Students might be grouped according to the steps to be taught and proceed in accordance with the attainment of criterion level performance on those steps rather than on the mean performance of the group or as a function of the passage of time. Presently, all of the necessary task analyses are not available for an ideal assessment system (all necessary skills analyzed from zero competence in an area to complete competence in that area). However, rapid progress is being made in some areas (e.g., math, see Resnick, Wang \& Kaplin, 1973); and it is the rare teacher who cannot do better than traditional inferential measurement devices.

Finally, before leaving this cursory treatment of instructional content, a note concerning the direction we feel content delineation should take might be in order. Whenever possible, we have chosen to emphasize the areas traditionally known as academic-i.e., speech and language, reading, math, and writing. Thus, we find ourselves in agreement with the 1967 position of Cawley and Pappanikou:

However, the success or failure of a human being in Western civilization has, is, and apparently will continue to be based upon one's ability to express oneself orally, to read, to write, to deal with number concepts, and to handle money.

With this in mind, then, it is indeed quite perturbing to the special educator who from time to time has to witness programs and discount academics on the pretense that birthday parties and craftwork are more important to the final integration, habilitation, and/or rehabilitation of the retarded in society. This is usually done in the name of personal and social adequacy. Such a change in curricular emphasis is looked upon by these authors more as an inability of that particular teacher to adapt methods of instruction appropriate to the aforementioned characteristics of her pupils, than as an inherent inability in the particular retardate to learn academics.

The reader interested in securing further information regarding instructional content that might be relevant to instruction programs might find the following selected references of interest: Becker, Englemann, and Thomas (1971); Bricker and Bricker (1972); Bricker and Bricker (1973); Bricker, Dennison, Watson, and Vincent-Smith (1973); Engelmann (1969); Molloy (1972); Sailor, Guess, and Baer (1973); Sheperd, Wyrick, and Bilyeu (1970); and Thiel (1972). 


\section{Method}

Method refers to the how of instruction. If a teacher asks the question "How do I get a student to do what he could not do in the past?" he or she is asking a method question. Specifically, method is concerned with how a teacher arranges the instructional environment, including his or her own behavior, so that enhancement of the behavioral repertoires of the students can be empirically verified.

Teaching students to make the responses that were delineated and sequenced in a task analysis is in our judgment the most difficult function the teacher performs. That is, a teacher can develop or purchase a precise and logical task analysis, utilize beautiful and relevant materials, and generate creative measurement systems; but if the teacher cannot teach the student to perform new responses, all is for naught. The techniques, tactics, procedures, principles, etc., that we employ related to the how of instructing severely handicapped students have been taken from the contributions of such persons as Itard, Sequin, Montessori, Descoeudres, Fernald, Strauss and Lehtinen, and Skinner.

Recently, however, we have found it useful to generate instructional methods from the conceptual framework of what is referred to as applied behavior analysis (Baer, Wolf \& Risley, 1968; Bandura, 1969). More specifically, we make conscientious attempts to systematically utilize such principles, tactics, procedures, etc., as response priming, imitation training, escape training, avoidance training, stimulus fading, stimulus discrimination and generalization, contingent consequation, overcorrection, errorless learning, and response chaining. Unfortunately, space does not permit a more detailed presentation of how the principles delineated above are converted for use in classroom instructional programs. The reader interested in such a presentation is referred to Brown, Bellamy, and Sontag (1971); Brown and Sontag (1972); and Brown, Scheuerman, Cartwright, and York (1973).

\section{Materials}

Once teachers determine the specific responses they intend to teach (i.e., what to teach), they then must determine the materials (persons, places, printed words, physical objects, etc.) to which those responses should be made. In other words, instructional materials should be generated subsequent to the delineation of instructional objectives. Unfortunately, there is an extreme dearth of sequenced instructional materials that have either been developed or empirically verified for classroom use with severely handicapped students. In general, it has been our experience that commercially available sequenced materials are not sufficiently concrete, precise, redundant, or relevant for use with most severely handicapped students. Thus, the teacher is forced to rely on his or her ingenuity to generate new or adapt existing materials.

It is expected that in the near future, because of the appearance of large numbers of severely handicapped students in public schools, a concerted effort on the part of commercial publishers and others will be made to develop much needed instructional materials. Hopefully, attempts will be made to empirically verify the validity of the materials prior to unrestricted dissemination. There is little doubt that the Wippie-dip Language, Reading, Math, Science, Motor, and Self-Help Contraption for Delayed, Low Functioning, Severely Handicapped But Needy Children will appear and be purchased by many "because there is nothing else available." However, such a dilemma is still uncomfortable.

\section{Measurement}

In any empirical definition of teaching, instructional measurement is crucial. With normal and mildly handicapped students, inferences about populations of skills made from samples and inferences about generalization of skills across persons and places and materials are probably necessary and tenable. Unfortunately, inferential measurement, in our judgment, is an extremely questionable measurement orientation when applied to most severely handicapped students. The general rule that we try to follow may be stated as follows: If you determine that a particular response, skill, concept, etc., is important to the development of the student, then it is incumbent upon the teacher to directly measure the existence of the response, skill, concept, etc., of concern. A related aspect of direct measurement may be stated as follows:

Direct measurement is particularly crucial in attempts to teach cumulative tasks. If the correct performance of the responses in component $\mathrm{c}$ of a task are dependent upon the correct performance of the responses in components $a$ and $b$, then the teacher must guarantee that $a$ and $b$ responses are in the behavioral repertoire of the student before she even considers progression to component c. Since most developmental skills are in many ways cumulative (mathematics, reading, language, speech, practical arts), teachers of trainable-level retarded students must be prepared to spend relatively long periods of time and considerable effort developing basic behavioral repertoires. [Brown, 1973]

Thus, it is necessary that teachers be skilled in the use of measurement designs that allow for the frequent and direct measurement of relevant behavioral dimensions. 
Frequent measurement is crucial if only to delineate instructional failure as soon as possible. That is, assume that a teacher designs and implements an instructional program in September, continues to implement that program until December, and then measures how much of the information, etc., in the program the students acquired. If the students acquired $100 \%$ of the information, fine. If, however, the students acquired none of the information, the teacher has wasted a substantialiamount of instructional time and energy. More frequent measurement would have allowed the teacher to delineate and adapt to instructional failure much sooner. On the other hand, direct and continuous measurement of all responses performed in the classroom throughout the entire school year is impractical, unnecessary, and irrelevant. Obviously, a balance has to evolve in each classroom with each student and each teacher.

In an attempt to provide teachers with a reasonable amount of flexibility regarding how much, how often, and what to measure directly, we have found it necessary to provide them with information, examples, and, in some situations, practice using some of the following subjects as their own controls paradigms and related measurement skills: reversal designs, learning set designs, trials to criterion and errors to criterion designs, multiple baseline and modifications of multiple baseline designs, test-teach designs, and cumulative frequency designs.

Hopefully, if teachers have a sufficient number of measurement designs in their technological repertoires, they will apply these designs to the evaluation of the instructional programs in their classrooms-thus enabling themselves to base daily or weekly adaptations in the content and methods of instruction upon student performance.

In summary, an instructional program requires a teacher (1) to determine what to teach students by precisely delineating behavioral objectives, (2) to determine how to teach students by clearly specifying his or her instructional activities, (3) to select or generate materials that require responses delineated in the behavioral objectives, and (4) to measure directly the responses of the students in an attempt to evaluate instructional effectiveness.

\section{THE POTENTIAL FOR BACKL: SH}

Thousands of severely handicapped children who were formerly accommodated at home, in private schools, in private and public residential institutions will now attend public schools. In the face of a restricting economic environment there are several potentially devastating reactions. It is extremely doubtful that many communities have at their disposal the additional economic resources necessary to secure the teachers, space, transportation, equipment, administrative personnel, etc., required to serve these new students. Most communities will have to reallocate resources currently assigned to other services.

If it can be demonstrated that a child who was once tied to a bed in an institution because he or she was self-mutilating can now read, write, compute, socialize, and in other ways behave more adaptively, few people will complain about giving up a new chemistry lab, new football uniforms, or small portions of their salary increases (Lovaas, 1974). If, on the other hand, a child who was tied to a bed in an institution is now tied to a bed in a public school classroom, it is doubtful that many persons will graciously accept the aforementioned economic adjustments. Obviously, the example of the child tied to a bed was used to dramatize a point. However, children sitting in classrooms finger painting for 10 months is less dramatic but will probably make the same point to the economically strapped taxpayer.

We believe the outcome of the placement of severely handicapped students in the school systems will be a function of the quality of the programs the school systems provide. Obviously, quality programs will be dependent upon the skills of the teachers hired to develop and maintain them. This, of course, makes the work of the trainers of these teachers extremely important.

Severely handicapped persons have not fared well in our society in the past. However, it seems that we now have an opportunity to create humane, tolerant, developmentally sound, and existentially relevant social and emotional environments that can replace the oppressive, rejecting, undignifying, and intolerant systems so long in operation. Hopefully, special education will supplement the activities of parents with varied contributions. Hopefully, among these contributions will be the production of aggressive and creative administrators capable of designing and engineering novel and flexible service delivery systems, and highly competent, dedicated, and efficient classroom teachers capable of providing quality instructional services over long periods of time. Finally, as we have so little in our technological repertoires that has any empirical validity, special education will have to generate a substantial body of new information specifically applicable to the instruction of severely handicapped persons. Stated another way, "we have to get special, nothing else works." 3

3. The reader will no doubt note the paucity of references in the body of this paper. The writers have compiled an outline for a course entitled "Methods of Instructing Severely Handicapped 
This paper was supported by Grant No. OEG-0-73-6137 to the University of Wisconsin-Madison from the Department of HEW, Bureau of Education for the Handicapped, Division of Training Programs, Washington, D.C.

\section{REFERENCES}

Baer, D. M., Wolf, M. M. \& Risley, T. R. "Some Current Dimensions of Applied Behavior Analysis." Journal of Applied Behavior Analysis, 1(1), 1968 (91-97).

Bandura, A. Principles of Behavior Modification. New York: Holt, 1969.

Bateman, B. The Essentials of Teaching. San Rafael, Calif.: Dimensions in Early Learning Series, 1971.

Becker, W. C., Engelmann, S. \& Thomas, D. R. Teaching: A Course in Applied Psychology. Chicago: Science Research Associates, 1971.

Bricker, D. \& Bricker, W. Toddler Research and Intervention Project: Report - Year II. Nashville: IMRID Behavioral Science Monograph No. 21, 1972.

Bricker, W. \& Bricker, D. "Early Language Intervention." Invited paper presented at NICHD Conference on Language Intervention with the Mentally Retarded, Wisconsin Dells, Wisconsin, June, 1973. Conference proceedings in press.

Bricker, D., Dennison, L., Watson, L. \& Vincent-Smith, L. Language Training Program for Young Developmentally Delayed Children: Volume 2. Nashville: IMRID Behavioral Science Monograph No. 22, 1973.

Brown, L. "Instructional Programs for Trainable-Level Retarded Students." In L. Mann \& D. A. Sabatino (Eds.), The First Review of Special Education, Vol. 2. Philadelphia: JSE Press, 1973.

Brown, L., Bellamy, T. \& Sontag, E. "The Development and Implementation of a Public School Prevocational Training Program for Trainable Level Retarded and Severely Emotionally Disturbed Students." Part I. Madison Public Schools, Madison, Wisconsin, 1971.

Brown, L., Scheuerman, N., Cartwright, S. \& York, R. "The Design and Implementation of an Empirically Based Instructional Program for Severely Handicapped Students: Toward the Rejection of the Exclusion Principle. Part III. Madison Public Schools, Madison, Wisconsin, 1973.

Brown, L. \& Sontag, E. "Toward the Development and Implementation of an Empirically Based Public School Program for Trainable Mentally Retarded and Severely Emotionally Disturbed Students." Part II. Madison Public Schools, Madison, Wisconsin, 1972.

Students." This outline includes substantial bibliographies in such areas as self-help skills, reading, math, behavioral management, language development, basic principles of acquisition and performance, instructional measurement and imitation training. This outline is available upon request (Dr. Lou Brown, 427 Education Building, University of Wisconsin, Madison, Wis. 53706). In addition, a bibliography related to curriculum content and materials for retarded students is available upon request.
Cawley, J. \& Pappanikou, A. J. "The Educable Mentally Retarded." In Haring, N. G. \& Schiefelbusch, R. L. (Eds.), Methods in Special Education. New York: MoGraw-Hill, 1967. Engelmann, S. Preventing Failure in the Primary Grades. Chicago: Science Research Associates, 1969.

Gilhool, T. K. Education: "An Inalienable Right." Exceptional Children, 39 (8), 1973 (597-609).

Lippman, L. \& Goldberg, I. I. Right to Education - Anatomy of the Pennsylvania Case and Its Implications for Exceptional Children. New York and London: Teachers College Press, 1973.

Lovaas, I. "An Interview by Paul Chance." Psychology Today, 7 (8), 1974 (76-84).

Mager, R. Preparing Instructional Objectives. Palo Alto, Calif. Fearson Pub., 1962.

Molloy, J. Trainable Children: Curriculum and Procedures. New York: John Day Co., 1972.

Resnick, L. B., Wang, M. C. \& Kaplan, J. "Task Analysis in Curriculum Design: A Hierarchically Sequenced Introductory Mathematics Curriculum." Journal of Applied Behavior Analy. sis, 6(4), Winter, 1973 (679-710).

( Sailor, W., Guess, D. \& Baer, D. M. "Functional Language for Verbally Deficient Children: An Experimental Program." Exceptional Children, 11(3), 1973 (27-35).

Schwartz, M. A. "The Education of Handicapped Children: Emerging Legal Doctrines." Clearinghouse Review (National Clearinghouse for Legal Services), 7(3), 1973.

Sheperd, B. W., Wyrick, R. P. \& Bilyou, D. Curriculum Guide for Teachers of Trainable Mentally Retarded Children. Jefferson City, Missouri: The Missouri State Department of Education Schools for Retarded Children, 1970.

Sontag, E., Burke, P. J. \& York, R. "Considerations for Serving the Severely Handicapped in the Public Schools." Education and Training of the Mentally Retarded, 8 (2), 1973 (20-26).

Swetlik, B. "Teaching Low Functioning Students Selected First, Second, and Third Person Singular Pronoun Expressive Language Responses to "Who-Doing" Questions." Unpublished manuscript, University of Wisconsin, 1974.

Thiel, E. A. Design for Daily Living: A Framework for Curriculum Development for Children and Youth with Mental Retardation. Quincy, Fla.: Thiel Enterprises, 1972.

Vergason, G. A. "Accountability in Special Education." Exceptional Children, 39(5), 1973 (367-373).

Focus on Exceptional Children back issues are available. Single copy of a back issue is $\$ 1.00$, while ten or more copies of the same issue are $50 \phi$ each.

Focus on Exceptional Children newsletter binder is now available for $\$ 3.50$.

Our subscription list has now been totally computerized. If the address on the label of your newsletter is incorrect or if you are moving, please let us know. Contact the Customer Service Department, Focus on Exceptional Children, 6635 East Villanova Place, Denver, Colorado 80222. 


\section{CLASSROOM} FORUM

\author{
Edited by Norma Boekel \\ University of Northern Colorado
}

\section{PROBLEM 34}

In my classroom of educable mentally handicapped there are several children who seem to be in constant motion. Can you suggest some techniques that might control their hyperactivity?

Knowing when to change activities, when to speed up or slow down is an asset to any good teacher. Unfortunately, most children lack this wisdom, and many of these children are tagged hyperactive. Among the questions you should ask yourself are:

1. Have I ruled out physical or health-related problems? A thorough physical examination may be in order.

2. Am I providing a learning atmosphere that is suitable? Look around. Perhaps you need to reduce the amount of visual and auditory stimuli.

3. Who is being bothered by all this unnecessary activity? (a) the other children? (b) the hyperactive children? (c) their teacher? If the answers to $a$ and $b$ are "no," you should consider helping out $c$. Try raising your own tolerance level.

4. Are these children being served by other professionals, such as psychologists, physical therapists, etc.? If so, you should keep in close contact with them to insure that your efforts are compatible.
5. Have I provided enough out of seat activities? According to Margaret Golick, "children-all children, but especially those with learning problemslearn best through activity, through doing something rather than sitting back passively and being told or shown. It may be partly because doing, touching, handling make things less abstract; it may be because of the element of discovery that doing brings; it may be because impulses from the muscles to the brain facilitate the learning process." You should vary all the interaction possibilities for a single task or routine! At any age level, your students should be provided with multisensory experiences. Listening and seeing should be combined with touching, testing, smelling, and appropriate motor activities.

6. Could the children's hyperactivity be a result of inner tension or excess muscle tonus? Relaxation therapy is one of the most effective and oftenoverlooked techniques that classroom teachers can incorporate into the daily curriculum. It can be beneficial to adults as well as children. If physical relaxation exercises are new to you, try Jacobson's techniques. (A series of films describing and illustrating the Jacobson techniques as applied to children is available from Learning Pathways, Inc., P. O. Box 1407, Evergreen, Colorado.) Another excellent resource is Bryant Cratty's book Active Learning, in which Chapter Two is devoted to "Calming Down and Tuning Up."

\section{REFERENCES}

Cratty, Bryant. Active Learning, Games to Enhance Academic Abilities. New York: Prentice-Hall, Inc., 1971.

Golick, Margaret. She Thought I Was Dumb But I Told Her I Had a Learning Disability. Toronto: Bryant Press Limited, 1969.

Jacobson, Edmund. Progressive Relaxation (2nd ed.). Chicago: Univ. of Chicago Press, 1938. 